\title{
Isolation and identification of microorganisms for polyurethane degradation
}

Julie D. Tan ${ }^{1 *}$ and Takuji Ohwada ${ }^{2}$

\begin{abstract}
Plastic wastes decomposition has been a pressing environmental problem worldwide. In this study, polyurethane (PUR), a thermoset plastic was tested for biodegradation by polyurethane-degrading microorganisms that were isolated from a dumpsite at Kamishihoro, Tokachi, Obihiro, Japan. Actinomycetes were the most abundant microorganisms from soil samples. From the 65 isolated microbial species, 16 possessed polyurethane-degrading ability. These isolates exhibited clearing zones on Yeast-extract salts + Agar and gelatin with polyurethane (YES-AG + PUR). The PUR-degrading isolates were characterized and identified based on their DNA sequence patterns. Some isolates belong to the same genus or species. They were Bacillus chitinolyticus (B03, B04, B07), Streptomyces spp. (B13, B19, C13a, C15, C17a, C17b), Pseudomonas sp. (B20), Bacillus pumilus (B21), Streptomyces cuspidosporus (C10b, C18, C19) and Pseudallesscheria baydii (F04, F07). Streptomyces sp. coded as C13a, with base sequence homology of $99.7 \%$ with Streptomyces albogriseolus, was believed to produce the highest amount of both exo-and endo-polyurethanases. This was demonstrated by the widest clearing zones when broth and cell-bound supernatants were inoculated into the YES-AG + PUR plate.
\end{abstract}

Keywords: Thermoset plastic, Actinomycetes, Coomassie Blue, Biodegradation

\section{INTRODUCTION}

Plastics are one of the most abundant solid wastes in the Philippines. They are considered major environmental pollutants since they are non-biodegradable due to the complexity of their compositions.

Practically, recycling of plastics has been identified as one of the solutions to

'Philippine Root Crop Research and Training Center, Visayas State University, Baybay City, Leyte 6521 Philippines

2Department of Life and Food Sciences, Obihiro University of Agriculture and Veterinary Medicine, Inada Cho Obihiro City, Japan 080-8555

*Corresponding Author. Address: Philippine Root Crop Research and Training Center, Visayas State University, Baybay City, Leyte6521 Philippines; Email:julie.tan@vsu.edu.ph 
the problem. About more than $50 \%$ of wastes from the developed countries are now being recycled (Child 2004). However, developing countries in Asia, like the Philippines, lag behind on waste recycling due to ineffective policies and lack of awareness of waste recycling processes (Jereme et al 2015). Most of the municipal solid wastes on developing countries contain potential recyclable materials of about $80 \%$ of the total wastes (Habitat International 1994). However, this method is labor-intensive and expensive considering the voluminous plastics to be sorted out each day. Furthermore, unless new and novel products can be produced from such wastes, this may worsen the problem of pollution if recycled products are still in complex form when disposed and remain non-biodegradable.

Plastics, in general, are either thermoplastics or thermoset. The thermoplastics are made up of the long and sole carbon chain, which provides resistance to degradation or hydrolytic cleavage of chemical bonds. Thus, they are considered as non-biodegradable plastics. Because of hydrophobicity, water repellency, high molecular weight and the absence of functional groups recognizable by microbial enzyme systems, thermoplastics (particularly polyethylene) are found resistant to biological action (Chiellini et al 2003). Furthermore, the presence of antioxidants in thermoplastics provides environmental stability of the polymer (Eggins et al 1971). Some researchers made attempts to make thermoplastics biodegradable: thermoplastics are blended with starch and antioxidants are reduced. However, without the addition of a suitable pro-oxidant, biodegradation merely causes the removal of starch and leave behind shorter chains of unmodified polyolefins (Zheng et al 2005). The addition of starch to polyolefins modifies their structures. In starch blends, there is a continuous starch phase that is favorable to microorganisms under the catalytic action of alpha- and beta- amylase enzymes. The continuous starch is then removed, resulting in porous polyolefin starch blends. In the presence of pro-oxidants, the degradation of the polyolefin matrix is accelerated.

Thermoset plastics are characterized by a highly cross-linked structure of heteroatoms which are believed to be responsible for their susceptibility to biodegradation (Zheng et al 2005). Thermoset plastics have not been considered useful, but recently, because of environmental pollution caused by plastic wastes, thermoset plastics are now seriously considered for various applications. Among the thermoset plastics, polyurethane (PUR) is recently gaining much attention in researches because of its increasing importance in industry, commerce, agriculture and medicine. The use of polyurethane has increased because of its high durability and resistance to degradation (Rowe \& Howard 2002). Polyurethanes are found almost everywhere. They are components of rubber adhesives, water-blown flexible foams, elastomers, coatings, fibers, foams in furniture, beddings, automobile cushions, thermal insulation on commercial vehicles and ships and medical devices (Ulrich 1983). This polymer represents the first industrially important and commercially useful culmination of an old line of organic research in isocyanates (Howard et al 1999). The polyurethane is suitable for varied applications due to its specific mechanical, physical, biological and chemical properties which can further be enhanced to suit its intended use (Akindoyo et al 2016).

Development of protocol to degrade the polymeric materials through microbial action has been identified as one of the most effective solutions in solving 
Isolation and identification of microorganisms

environmental pollution. In this study, therefore, microorganisms were isolated from dumpsites, screened for polyurethane degradation and identified.

\section{MATERIALS AND METHODS}

\section{Isolation and Purification of Microorganisms from Dumpsite Soil}

Thirty bags of randomly selected soil samples (approximately $200 \mathrm{~g}$ each) from the dumpsite soil in Kamishihoro, Tokachi, Obihiro, Japan were collected and brought to the laboratory for microbial isolation. The isolates were purified using appropriate growth medium for each type of microorganisms. The isolation media were sodium caseinate agar (SCA) for Actinomycetes, Potato Dextrose Agar (PDA) for fungi and Nutrient Agar (NA) for bacteria. The pure cultures were stored in $20 \%$ glycerol at $-80^{\circ} \mathrm{C}$ until use.

\section{Screening of Microorganisms for Polyurethane Degradation}

The microorganisms were screened for their abilities to degrade polyurethane following the method described by Crabbe et al (1994) and Howard et al (1999) with some modifications.

Preparation of basal medium and polyurethane substrate. Yeast-extract salts (YES) medium was used for qualitative screening of microorganisms for their abilities to degrade polyurethane. A step-wise combination of four stock solutions was prepared (Table 1).

Table 1. Yeast-Extract Salts Medium

\begin{tabular}{ll}
\hline \multicolumn{1}{c}{ Stock Solution } & \multicolumn{1}{c}{ Composition } \\
\hline A (50x phosphate buffer, pH7.4 (Dash \& Cudworth & $197 \mathrm{~mL} \mathrm{KH}_{2} \mathrm{PO}_{4}\left(9.10 \mathrm{~g} \mathrm{~L}^{-1}\right)$ \\
2001) & $803 \mathrm{~mL} \mathrm{Na}_{2} \mathrm{HPO}_{4}\left(9.48 \mathrm{~g} \mathrm{~L}^{-1}\right)$ \\
B (100x magnesium sulfate) & $\mathrm{MgSO}_{4} .7 \mathrm{H}_{2} \mathrm{O}\left(50 \mathrm{~g} \mathrm{~L}^{-1}\right)$ \\
C (1000x trace metals) & $\mathrm{MnCl}_{2} .4 \mathrm{H}_{2} \mathrm{O}, 2000.0 \mathrm{mg} \mathrm{L}^{-1}$ \\
& $\mathrm{CuCl}_{2} .2 \mathrm{H}_{2} \mathrm{O}, 28.0 \mathrm{mg} \mathrm{L}^{-1}$ \\
& $\mathrm{ZnCl}_{2}, 22.0 \mathrm{mg} \mathrm{L}^{-1}$ \\
& $\mathrm{CaCl}_{2} .6 \mathrm{H}_{2} \mathrm{O}, 40.0 \mathrm{mg} \mathrm{L}^{-1}$ \\
& $\mathrm{Na}_{2} \mathrm{MoO}_{4} .2 \mathrm{H}_{2} \mathrm{O}, 26.0 \mathrm{mg} \mathrm{L}^{-1}$ \\
& $\mathrm{FeCl}_{3} 6 \mathrm{H}_{2} \mathrm{O}, 150 \mathrm{mg} \mathrm{L}^{-1}$ \\
& Yeast Extract $\left(10.0 \mathrm{~g} \mathrm{~L}^{-1}\right)$ \\
\hline
\end{tabular}

Preparation of Yeast-extract salts + Agar and gelatin with polyurethane (YES$A G+P U R)$. $A 20 \mathrm{~mL}$ portion of stock solution A was added to $970 \mathrm{~mL}$ distilled water. Purified agar $(1.5 \% \mathrm{w} / \mathrm{v}),\left(\mathrm{NH}_{4}\right)_{2} \mathrm{SO}_{4}(0.5 \mathrm{~g})$ and gelatin $(4.0 \mathrm{~g})$ were added, and the solution was heated to dissolve the agar. The solution was autoclaved at $121^{\circ} \mathrm{C}$ for $20 \mathrm{~min}$ and allowed to cool to $50^{\circ} \mathrm{C}$. While the temperature of solution $\mathrm{A}$ was maintained at $50^{\circ} \mathrm{C}, 10 \mathrm{~mL}$ of filter-sterilized solution $B$ was added with constant stirring. Likewise, $1 \mathrm{~mL}$ of filter-sterilized solution $C$ and $2 \mathrm{~mL}$ of solution $D$ were then added with constant stirring. The sequence of each step and the temperature were strictly followed to prevent the formation of insoluble phosphates. The main 
substrate was added in the prepared solution in the form of a milky white, liquid PUR 860 from Daiichi Kogyo Seiyaku, Superflex Company, Japan. PUR 860 is an ester/aromatic isocyanate-based, water-dispersed solution. The prepared YES-AG + PUR was dispensed in plates at about $20 \mathrm{~mL}$ each and the agar was allowed to solidify. The agar plates were stored at $4^{\circ} \mathrm{C}$ if not immediately used.

Inoculation of microorganisms on the YES-AG + PUR plate. Bacteria and Actinomycetes were streaked into the YES-AG + PUR plate. Since fungi grow fast and spread profusely in the agar plate, they were simply spot inoculated once in the center of the agar plate. Using the mouth of a sterilized Pasteur pipet, $8 \mathrm{~mm}$ diameter plug of the fungal isolate was dug from a confluent surface growth of isolate on a PDA plate. Using a sterile stainless steel spatula, the surface growth was separated from the underlying agar plug and inoculated into the center of YESAG + PUR plate.

Testing of enzyme activities of the isolates. The top-five isolates that exhibited clearing in YES-AG + PUR plates were grown in YES broth with PUR 860 under an agitated condition at $120 \mathrm{rpm}$ at $30^{\circ} \mathrm{C}$ for seven days. The fermented broth was centrifuged at $10,000 \mathrm{xg}$ for $10 \mathrm{~min}$ and the supernatant was separated from the cell pellets. The cell pellets were stored at $-20^{\circ} \mathrm{C}$ for one day. The supernatant was filtered using $0.45 \mu \mathrm{m}$ cellulose acetate. The presence of PUR-degrading enzymes in the filtered supernatant $\mu$ was tested by inoculating $100 \mu \mathrm{L}$ into $6 \mathrm{~mm}$ wells dug in YES-AG plates with PUR 860. A rapid method of detecting PUR-degrading enzymes by Howard and Hilliard (1999) was used. The plates were incubated for 18 to $20 \mathrm{~h}$ at $37^{\circ} \mathrm{C}$ and then flooded with $0.1 \%(\mathrm{w} / \mathrm{v})$ Coomassie blue R-250 solution in $40 \%(\mathrm{v} / \mathrm{v})$ methanol and $10 \%(\mathrm{v} / \mathrm{v})$ acetic acid for $20 \mathrm{~min}$. The Coomassie blue solution was decanted and the plates were flooded with $40 \%(\mathrm{v} / \mathrm{v})$ methanol and $10 \%(\mathrm{v} / \mathrm{v})$ acetic acid for 20min. PUR-degrading enzymes developed clear zones around the well.

After one day of freezing the cell pellets, $10 x(\mathrm{w} / \mathrm{v})$ of $20 \mathrm{mM}$ potassium phosphate buffer with $0.2 \% \mathrm{~N}, \mathrm{~N}^{1}$-bis(3-D-gluconamidopropyl) deoxycholamide (DEOXY BIG CHAP) was added and the mixture was stirred vigorously for $30 \mathrm{~min}$ at room temperature. The mixture was then centrifuged at $10,000 \mathrm{xg}$ for $10 \mathrm{~min}$ and the supernatant was filtered using $0.45 \mu \mathrm{m}$ cellulose acetate. The filtered cell-bound supernatant was assayed for PUR-degrading enzyme in $6 \mathrm{~mm}$ wells dug in YES-AG plate.

Selection, characterization and identification of polyurethane-degrading microorganisms. The 16 isolates that exhibited PUR-degrading abilities were characterized taxonomically through DNA sequencing analysis. DNA from toughto-lyse fungi was isolated following the more recent, simple and rapid isolation method described in ZR Fungal/Bacterial Kit (Zymo Research Corporation 2007). The DNA from fungi were extracted and ITS region was amplified using primer pairs of ITS1/ITS4 in the following conditions: $3 \mathrm{~min}$ at $94^{\circ} \mathrm{C}, 40$ cycles of $30 \mathrm{~s}$ at $94^{\circ} \mathrm{C}, 30 \mathrm{~s}$ at $50^{\circ} \mathrm{C}, 1 \mathrm{~min}$ at $72^{\circ} \mathrm{C}$ and one final step of $10 \mathrm{~min}$ at $72^{\circ} \mathrm{C}$. For bacteria, the primers used were rD1 and $\mathrm{fD} 1$ and amplified at the following conditions; $3 \mathrm{~min}$ at $93^{\circ} \mathrm{C}, 45$ cycles of $30 \mathrm{~s}$ at $93^{\circ} \mathrm{C}, 15 \mathrm{~s}$ at $50^{\circ} \mathrm{C}, 1.5 \mathrm{~min}$ at $72^{\circ} \mathrm{C}$ and one final step of $7 \mathrm{~min}$ at $72^{\circ} \mathrm{C}$.

The amplified products were purified and mixed with primers and the $A B I$ PRISM BigDye Terminator Cycle Sequencing Ready Reaction Kit (Applied Biosystems) containing a fluorescent dye. Then an extension reaction was carried out by PCR following the procedure recommended by the manufacturer. The 
Isolation and identification of microorganisms

fragments were sequenced in both directions using an ABI PRISM 3100 DNA Sequencing System, according to the manufacturer's instructions. The sequences obtained were compiled and compared with those in the GenBank databases through the National Center for Biotechnology Information (NCBI), using BLASTsearch.

\section{RESULTS AND DISCUSSION}

A total of 65 microbial strains were isolated from the soil in a dumpsite in Kamishihoro, Japan (Table 2). Actinomycetes were found the most abundant, followed by other types of bacteria and then fungi. Actinomycetes are the most abundant organisms in the soil which inhibit the growth of plant pathogens, decompose complex mixtures of polymer and produce extracellular enzymes for crop production (Bhatti et al 2019). From the isolated and purified species, only 16 isolates exhibited positive activity on PUR. Of these 16 isolates, there were 7 Actinomycetes, 7 bacteria and 2 fungal species. Likewise, an actinomycete species, identified as Streptomyces rochei, was found efficient in degrading plastics particularly polyethylene bags and bottles (Nakei 2015).

Table 2. Total number of isolates exhibiting polyurethane degradation

\begin{tabular}{lcc}
\hline Types of microorganisms & Total Number & $\begin{array}{c}\text { Number of microorganisms with } \\
\text { positive activity on PUR }\end{array}$ \\
\hline Bacteria & 27 & 7 \\
Actinomycetes & 23 & 7 \\
Other types of Bacteria & 15 & 2 \\
Fungi & 65 & 16 \\
\hline Total & & \\
\hline
\end{tabular}

The PUR-degrading ability was demonstrated by the formation of clearing zones on YES-AG + PUR Plate. Figure 1 clearly shows the clearing and non-clearing zones that were formed by the PUR-degrading and non-PUR-degrading isolates, respectively. The formation of clearing zones was enhanced with Coomassie blue which acts as an indicator for PUR degradation by the isolate in YES-AG + PUR Medium. The detection of the polyurethane-degrading enzyme in the agar medium is based on the ability of enzymes to depolymerize the substrate. Consequently, upon hydrolysis of the substrate, the interaction of the Coomassie blue with the polyurethane is reduced, resulting in a clear zone within a blue background (Howard \& Hilliard 1999).

The biodegradation of polyurethane is initiated by surface erosion process by microbial enzymes, which eventually produces water-soluble intermediates that can be assimilated by microbial cells (Muller et al 2001). The chemical process that occurs during biodegradation is divided into two categories, namely, (1) assimilatory process, in which constituents of the plastics serve as sources of nutrients to organisms and (2) dissimilatory processes, in which the plastics are not used as a source of carbon but maybe chemically damaged by corrosive substances secreted by an organism living on detritus lying on the plastics (Eggins et al 1971). 

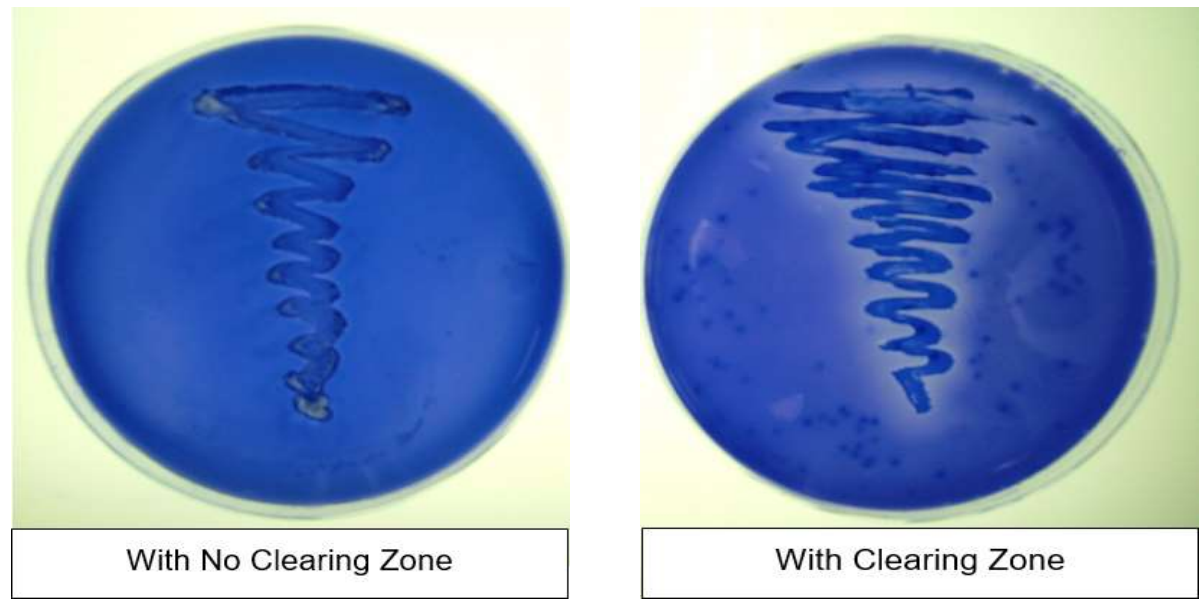

Figure 1. Isolates showing non-clearing and clearing zones on YES-AG Agar Plate

The PUR-degrading isolates were identified base on their DNA sequence patterns. Table 3 presents the identification of the 16 PUR-degrading isolates. They were Bacillus chitinolyticus (B03, B04, B07), Streptomyces spp. (B13, B19, C13a, C15, C17a, C17b), Pseudomonas sp. (B20), Bacillus pumilus (B21), Streptomyces cuspidosporus (C10b, C18, C19) and Pseudallesscheria baydii (F04, F07).

Table 3. Identification of the isolates

Isolate Code Name/Identification

\begin{tabular}{ll}
\hline Actinomycetes & \\
C10b, C18, C19 & Streptomyces cuspidosporus \\
B13, B19, C13a, C15, C17a, C17b & Streptomyces spp. \\
Bacteria & \\
B20 & $\begin{array}{l}\text { Pseudomonas sp. } \\
\text { B21 }\end{array}$ \\
B03, B04. B07 & Bacillus pumilus \\
& \\
Fungi & \\
F04b, F07 & Pseudallesscheria baydii \\
\hline
\end{tabular}

The measurement of clearing zones of the top 5 PUR-degrading microorganisms is presented in Figure 3 . From the 5 isolates, 4 belonged to Streptomyces spp., while 1 isolate was identified as Bacillus pumilus. Although C17a (Streptomyces sp.) formed the widest clearing zone, it did not exhibit the clearest zone. In general, C13a, which also belongs to Streptomyces sp., consistently formed wider and clearer zones than the others, both in broth and cellbound supernatant. The strain $\mathrm{C} 13 \mathrm{a}$ is closely related to Streptomyces albogriseolus with base sequence homology of $99.7 \%$. 
Isolation and identification of microorganisms

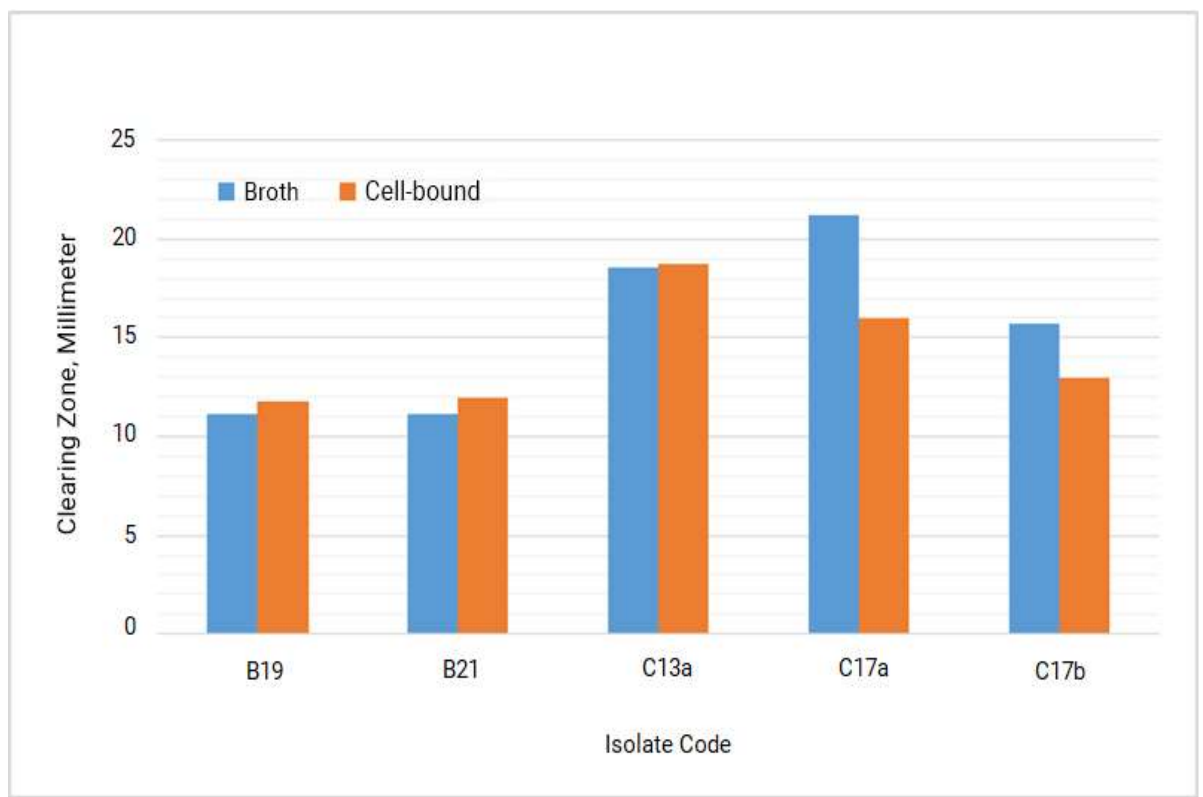

Figure 2. Clearing zones ( $\mathrm{mm}$ ) of the top PUR-degrading microorganisms in YES-AG + PUR plates

As reported by Crabbe et al (1994) and Howard et al (1999), the PUR is degraded by the combined activities of endo-polyurethanase (alpha) and exo-polyurethanase (beta), which formed incomplete and complete clearing zones, respectively. It is possible, therefore, that both endo- and exo-polyurethanase are produced by $\mathrm{C} 13 \mathrm{a}$ in both broth and cell-bound supernatant. Incomplete or indistinct clearing zones formed by other isolates might have been brought about by the activity of endopolyurethanase only. Vigorous stirring and centrifugation of the cells in the presence of DEOXY BIG CHAP ,to dislodge cell-bound enzyme, released the endopolyurethanase from within the cells. Polyurethanes, especially the polyester type, possess many ester bonds that can be hydrolyzed (Nakajima-Kambe et al 1999). The process involves endo-type depolymerization.

Based on the results of this study, C13a strain has proven to be a very potential isolate for polyurethane degradation and believed to produce both endo- and exopolyurethanases. Undoubtedly, the use of this microorganism in solving the country's problem on solid wastes, particularly plastics, is very promising. Further tests to confirm its identification can be done and this strain can also be tested in other types of plastics that are commonly found in solid wastes. 
Tan \& Ohwada

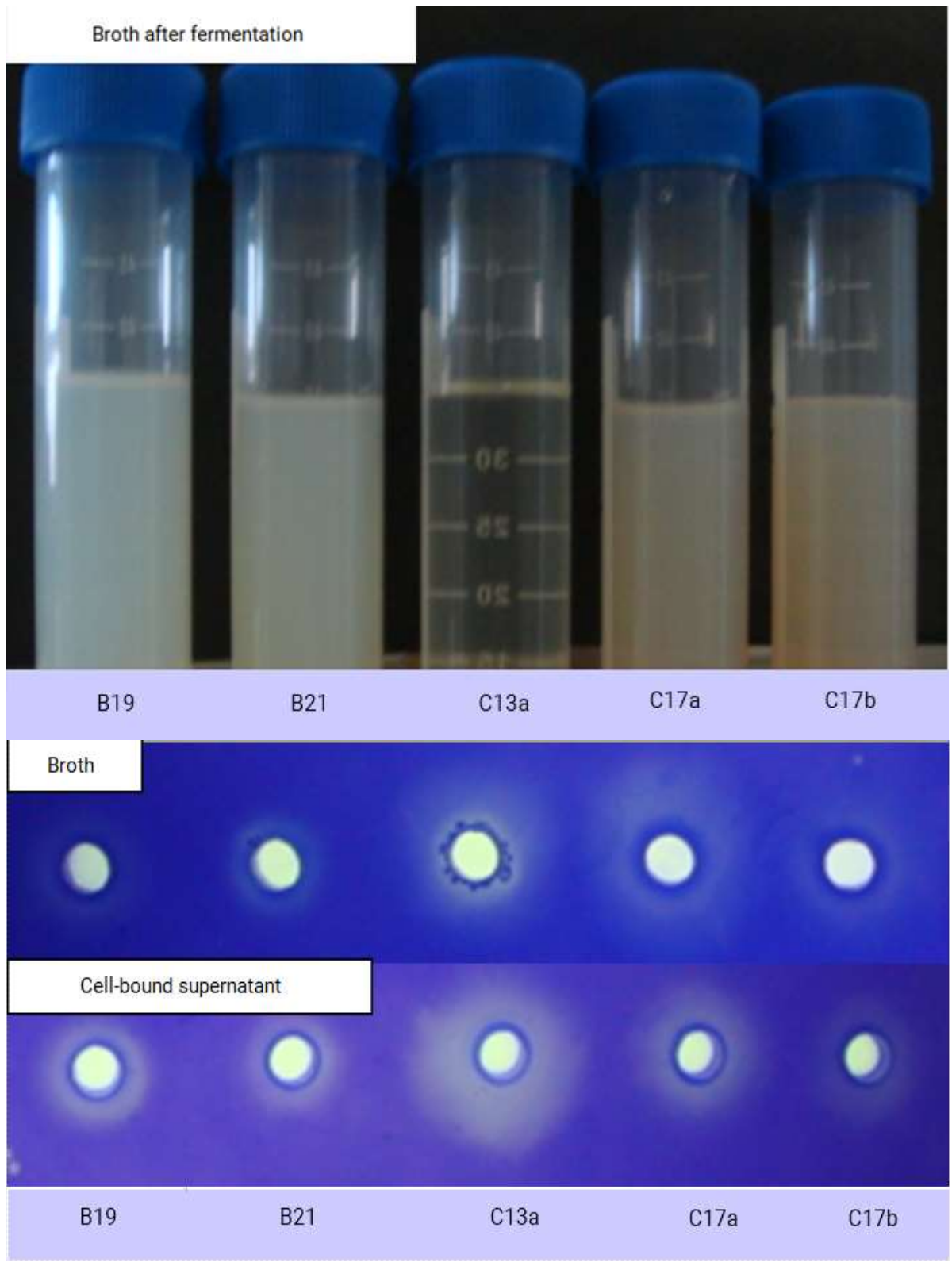

Figure 3. Formation of clearing zones in broth and cell-bound supernatant by the top five PURdegrading isolates

\section{CONCLUSION AND RECOMMENDATION}

Actinomycetes belonging to Streptomyces $\mathrm{sp}$. with base sequence homology of $99.7 \%$ with Streptomyces albogriseolus, possessed the highest PUR-degrading 
Isolation and identification of microorganisms

ability among the microbial isolates from a dumpsite soil in Kamishihoro, Japan. The isolate was believed to produce endo- and exo-polyurethanase, as shown by clearing zones when both fermented broth and cell-bound supernatant were inoculated in YES-AG + PUR. Optimization of conditions for increased production of these enzymes is recommended, considering the voluminous thermoset plastics being disposed daily. The identification of this microorganism needs further confirmation and it can also be tested in other kinds of plastic wastes.

\section{ACKNOWLEDGMENT}

The conduct of this study was made possible through the financial support of the HEIWA NAKAJIMA Foundation (Japan), Microbiology Laboratory of the Department of Life and Food Sciences, Obihiro University of Agriculture and Veterinary Medicine, Inada Cho Obihiro City (Japan) and the Visayas State University, Baybay City, Leyte (Philippines).

\section{REFERENCES}

Akindoyo JO, Beg MDH, Ghazali S, Islam MR, Jeyaratnam N \& Yuvaraj AR. 2016. Polyurethane Types, Synthesis and Applications - A Review. Royal Society of Chemistry Advances 6:114453-114482

Akutsu Y, Nakajima-Kambe T, Nomura N \& Nakahara T. 1998. Purification and Properties of a Polyester Polyurethane-Degradig Enzyme from Comamonas acidovorans TB-35. Applied and Environmental Microbiology 64(1):62-67

Bhatti AA, Haq S \& Bhat RA. 2017. Actinomycetes benefaction role in soil and plant health. Microbial Pathogenesis 111:458-467

Bradford MM. 1976. A Rapid and Sensitive Method for the Quantitation of Microgram Quantities of Protein Utilizing the Principle of Protein-Dye Binding. Analytical Biochemistry 72(1-2):248-254

Chiellini E, Corti A \& Swift G. 2003c. Biodegradation of thermally-oxidized, fragmented low-density polyethylenes. Polymer Degradation and Stability 81:341-351

Child R. 2004. Resource Conservation and Recycling Cliff. Borough Council Recycling Progress Report in Eastern London (pp1-25)

Crabbe JR, Campbell JR, Thompson L, Walz SL \& Schultz WW. 1994. Biodegradation of a colloidal ester-based polyurethane by soil fungi. International Biodeterioration and Biodegradation 33(2):103-113

Eggins HO, Mills J, Holt A \& Scott G. 1971. Biodeterioration and biodegradation of synthetic polymers. Society for Applied Bacteriology Symposium Series 1(1):267-279

Howard GT and Hilliard NP. 1999. Use of Coomassie blue-polyurethane interaction in screening of polyurethane proteins and polyurethanolytic bacteria. International Biodeterioration and Biodegradation 43(1-2):23-30

Howard GT and Blake RC. 1998. Growth of Pseudomonas fluorescens on a polyester-polyurethane and the purification and characterization of a polyurethanase-protease enzyme. International Biodeterioration and Biodegradation 42(4):213-220 
Howard GT, Vicknair J \& Mackie I. 2001. Sensitive plate assay for screening and detection of bacterial polyurethane activity. Letters in Applied Microbiology 32(3):211-214

Jereme IA, Siwar C \& Alam MM. 2015. Waste Recycling in Malaysia: Transition from Developing to Developed Country. Indian Journal of Education and Information Management 4(1):1-14

Kaseva ME and Mbuligwe SE. 2005. Appraisal of solid waste collection and private sector involvement in Dar es Salaam City, Tanzania. Habitat International 29(2):353-366

Kay MJ, Mccabe RW \& Morton LHG. 1993. Chemical and Physical Changes Occurring in Polyester Polyurethane During Biodegradation. International Biodeterioration and Biodegradation 31(3):209-225

Muller R, Kleeberg I \& Deckwer W. 2001. Biodegradation of polyesters containing aromatic constituents. Journal of Biotechnology 86(2):87-95

Nakajima-Kambe T, Onuma F, Akutsu Y \& Nakahara T. 1997. Determination of the Polyester Polyurethane Breakdown Products and Distribution of the Polyurethane Degrading Enzymes of Comamonas acidovorans Strain TB-35. Journal of Fermentation and Bioengineering 83(5):456-460

Nakajima-Kambe T, Shigeno-Akutsu Y, Nomura N, Onuma F \& Nakahara T. 1999. Microbial degradation of polyurethane, polyester polyurethanes and polyether polyurethanes. Applied Microbiology and Biotechnology 51(2):134-140

Nakei MD. 2015. Isolation and Identification of Plastic-degrading Microorganisms from Soils of Morogoro, Tanzania (MS thesis). Sokoine University of Agriculture, Morogoro, Tanzania

Rowe L and Howard GT. 2002. Growth of Bacillus subtilis on polyurethane and the purification and characterization of a polyurethanase-lipase enzyme. International Biodeterioration and Biodegradation 50(1):33-40

Fried JR. 1995. Polymer Science and Technology (3rd edn) (pp509). Prentice-Hall, PTR, Englewood CliHs, New Jersey

Ulrich H. 1983. Polyurethane. In Modern Plastics Encyclopedia 60(10a):76-84. McGraw-Hill, New York

Zheng Y, Yanful EK \& Bassi AS. 2005. A review of plastic waste biodegradation. Critical Reviews in Biotechnology 25(4):243-250 